\section{MUJERES DE CINE: DEL GLAMOUR DE HOLLYWOOD A LOS MODELOS ALTERNATIVOS}

\author{
María Caballero Wangüemert \\ Universidad de Sevilla \\ mcaballero@us.es
}

\section{FILM WOMEN: FROM HOLLYWOOD'S GLAMOUR TO ALTERNATIVE MODELS}

Cómo citar este artículo/Citation: Caballero Wangüemert, M. (2016). "Mujeres de cine: del glamour de Hollywood a los modelos alternativos". Arbor, 192 (778): a306. doi: http:// dx.doi.org/10.3989/arbor.2016.778n2009
Copyright: (c) 2016 CSIC. Este es un artículo de acceso abierto distribuido bajo los términos de la licencia Creative Commons Attribution (CC BY) España 3.0.
RESUMEN: Es un hecho que el cine ha reflejado la revolución de mujer, familia y sociedad en el siglo XX. El cine nace en masculino: es el hombre quien desempeña las funciones públicas mientras la mujer reina en el ámbito privado, educando desde el hogar a los futuros ciudadanos. ¿Es suficiente ese papel para la mujer actual? Desde luego que no y de ahí su Aasalto al poder: en el caso del cine, la mujer ha pasado de ser objeto de deseo, la protagonista de la historia amorosa en las comedias de Hollywood, a comandar la aventura del séptimo arte como guionista ( $E$. Thompson, R. P. Jhavbala, Diablo Cody), productora (B. Streisand, I. Bollaín) y, sobre todo, directora: la propia Streisand, M. von Trotta, S. Coppola, A. Huston... pero también M. Nair, D. Metha, I. Bollaín, I. Coixet, G. Querejeta, K. Bigelow, L. Schefig, S. Bier, N. Labaki, M. Ruíz de Austri... Mi trabajo da por supuesta esa diacronía, para plantearse una pregunta: ¿qué tipos de familia y qué problemáticas femeninas nos acerca últimamente la gran pantalla?

PALABRAS CLAVE: Mujer; cine; roles femeninos; familia; trabajo; sociedad del siglo XXI.
ABSTRACT: Cinema has reflected the great changes that women, family and society have undergone in the twentieth century. Film was born male, but throughout the twentieth century, woman has gone from being an object of desire, the star of the love story in Hollywood comedies, to commanding the adventure of cinema as a screenwriter ( $E$. Thompson, RP Jhavbala ), producer (B. Streisand, I. Bollaín) and, especially, director: Streisand, M. von Trotta, S. Coppola, A. Huston among others, but also M. Nair, D. Mehta, I. Bollaín, I. Coixet, G. Querejeta, K. Bigelow, L. Schefig, S. Bier, N. Labaki, M. Ruiz de Austri. This paper assumes the validity of this diachrony, in order to consider one question: What kind of family models and what kind of women's models does the big screen provide us with, beyond the old dichotomy of angel/ whore?

KEYWORDS: Female models; family models; cinema; female identity; society of 21th century. 
¿Desde qué ángulo abordar un tema tan apasionante como mujer y cine? Tal vez comenzando por las mujeres excepcionales de la historia, una Greta Garbo vestido de hombre y proa al viento en su papel de La reina Cristina de Suecia (1933, Mamoulian). O la María Antonieta (2000) que humaniza en una visión rompedora la hija de Coppola. Por qué no la Teresa de Jesús de Gordon (Teresa, Teresa (2003) o la Hildegarda que Margarette von Trotta lleva a la pantalla en Visión (2009), películas minoritarias y discutibles donde las haya, aunque valiosas. Reinas, monjas... hasta casi el siglo XX había que serlo para acceder a la cultura y al poder. Más apasionante aún, podría resultar revivir a las sufragistas norteamericanas y su campaña en favor del voto femenino. Incluso resultaría tentador abordar luchadoras contemporáneas como la Agnes Browne o la Erin Brockovich que se jugaron el tipo en pro de una apertura política o de la denuncia de las multinacionales antiecologistas. Muy popular la segunda, llevada a la pantalla por Soderbergh (2000) y encarnada por una Julia Roberts muy creíble; mientras que Agnes Browne (1999) es la primera aventura en la dirección de la excelente actriz Anjelica Huston. Ambas reflejan los claros y sombras de una mujer que debe sacar adelante a su familia en soledad: el rol de madre soltera o abandonada se abre paso.

La bibliografía actual sobre las mujeres de celuloide es cada vez más amplia y lo es por doble motivo: el cine ha reflejado la revolución de mujer, familia y sociedad en la segunda mitad del siglo XX. Y si bien al principio lo hizo "en masculino" porque en sus orígenes fue así, inmediatamente reflejó el "asalto al poder" de una mujer que ha pasado de ser objeto de deseo, la protagonista de la historia amorosa en las comedias de Hollywood, a comandar la aventura del séptimo arte saltando a la palestra como guionista ( $E$. Thompson, R. P. Jhavbala, Diablo Cody), productora (B. Streisand, I. Bollaín) y, sobre todo, directora: la propia Streisand, M. von Trotta, S. Coppola, A. Huston... pero también M. Nair, D. Metha, I. Bollaín, I. Coixet, G. Querejeta, K. Bigelow, L. Schefig, S. Bier, N. Labaki, M. Ruíz de Austri... Algo de ello queda patente en un libro que coordiné hace algunos años, Mujeres de cine. 360 o alrededor de la cámara (2011). La estructura de mi exposición en este artículo tiene evidentes deudas con mi trabajo acerca de las directoras en aquel libro. Me propongo ahora un breve recorrido por la pantalla cinematográfica, ampliándola a los últimos años, para refrescar cómo se hizo eco el séptimo arte de algunas cuestiones anejas al feminismo, la ruptura de la familia patriarcal y los nuevos roles, fenómenos definitivos en la reestructuración sociopolítica del siglo XX que alcanzan hasta hoy. Porque es indudable el impacto de la ficción llevada al cine en la vida de personas y sociedades.

Siempre, el hilo conductor será la mujer, en su rol de madre y ama de casa, o en su vertiente cada vez más habitual de trabajadora fuera de ella, en pro de una anhelada, problemática o frustrada realización personal.

\section{EL CINE REESCRIBE LA LUCHA FEMENINA POR AC- CEDER AL TRABAJO}

Para glosar este asunto he elegido Yentl (1983), un texto fílmico sobre la reivindicación educativa de las mujeres escrito, protagonizado, producido y dirigido por B. Streisand. El guión aprovecha un relato del nobel judío Singer sobre una comunidad judía de Europa oriental hacia 1904 y se sostiene más por el mensaje que por la historia (la renuncia femenina al amor en pro del estudio), demasiado folletinesca en su trama final. Al tratarse de un musical, el mensaje feminista se expresa en las canciones: "dime dónde está escrito que no debo atreverme a alcanzar la fruta de cada árbol", cantará la protagonista, en una clara alusión al famoso episodio de la manzana en el paraíso. Y para ello se enfrentará a la tradición de su comunidad que dice: "la mujer no puede pensar por sí misma" y "la que conoce el Talmud es como un demonio"... lo que no cambiará hasta la última secuencia, una secuencia musical centrada en el barco que le lleva a un Nuevo Mundo lleno de posibilidades. Por ello, podrá afrontarlo desde la condición femenina, vestida como tal.

En relación al tema que nos ocupa son muy conocidas las adaptaciones cinematográficas de Austen, la novelista inglesa más popular por la riqueza de matices de su escritura y su sorprendente capacidad para trazar psicologías femeninas (y masculinas) y describir el complejo tejido social de su época; sorprendente teniendo en cuenta que fue hija de un vicario campesino y viajó muy poco. Sentido y sensibilidad (1995), de Ang Lee, más aún Mansfield Park (1999), de Patricia Rozema y Orgullo y prejuicio en la producción de la BBC con una fantástica Rómula Garay plantean la problemática femenina en los umbrales del XIX como una alternativa sin salida: el espacio de la mujer decente es el hogar; si no, es una perdida. ¿Es perceptible el sello masculino / femenino en la dirección de Ang Lee o la de Patricia Rozema? Quizá no tanto, hay que recordar la sensibilidad extrema del director taiwanés y su interés en los temas familiares. Y que la guionista de su película es Enma Thompson, que borda su trabajo convirtiendo en mi- 
radas, gestos, explosiones de llanto sin palabras lo que en el texto de Austen ocupa varias páginas. Aún así, a nivel textual la protagonista de Mansfield... es más moderna y reivindicadora de su independencia: ¿algo achacable a la dirección femenina?

¿Existen atajos para triunfar en un mundo masculino? El cine se hace eco de cómo, en su obsesión por incorporarse a la esfera laboral y ciudadana, la mujer copia las malas artes masculinas: todo vale para triunfar en Eva al desnudo (1950), la excelente película de Mankievicz (cuyo remake si bien con final feliz podría ser The Artist, 2011, ganadora de un Óscar), o en Armas de mujer (1988), donde una de las féminas despluma a la otra en su loca carrera por situarse profesionalmente en el mundo masculino. Son películas dirigidas por hombres que se distancian de los matices y registros de una película sutil, An Education (2010), dirigida por la danesa Lone Schefig. Muestra las tentaciones que se le ofrecen a una joven británica de los sesenta para atajar el camino del éxito: venderse al hombre maduro, renunciar a la honradez. Algo que se paga muy caro y que la joven protagonista evitará tras asomarse al precipicio, reconstruyendo su vida a golpe de estudio y trabajo bien hecho. ¿El premio? Ella misma. La mujer llegará a través de su esfuerzo, no se prostituirá.

La educación fue el campo por el que la mujer abrió brecha en su búsqueda de trabajo remunerado y reconocimiento social. Al menos en el ámbito occidental, la mujer como docente lleva más de un siglo asentada y el cine parece no cansarse de llevarla a la pantaIla. Como muestra, tres historias que recientemente triunfaron: La historia de Marie Heurtin (2014, J.-P. Amèris), La profesora de historia (2014, guión y dirección de Marie-Castille Mention Schaar) y Conducta (2014, E. Daranas).

La primera, que recuerda El milagro de Anna SuIlivan (1962) un film de A. Penn ampliamente oscarizado, es una película francesa basada en una historia real: la protagonista es una pequeña salvaje, una niña sorda y ciega cuyo padre lleva a un convento para una educación que parece utópica. Solo la acogida y dedicación full time de la hermana Marguerite, capaz de ver una persona donde nadie la ve, conseguirán el milagro. El guión, del propio director en colaboración con Philippe Blasband, muestra que también los hombres son capaces de auténtica empatía con el imaginario femenino. Buena música y fotografía, excelentes interpretaciones, en especial de la protagonista Ariana Rivoire, una debutante actriz sordomuda.
En cuanto a La profesora de historia, es la tercera entrega de su directora, que muestra ahora su madurez. El relato sobre una profesora (Ariane Ascaride) empeñada en motivar a alumnos conflictivos de aulas multirraciales en la banlieue parisina, refleja una historia real. Incentivarlos a través de la participación en un concurso nacional es una excusa para lograr su integración y hacerles madurar; lo que centra mucho el desarrollo del film en el aula, si bien se abre al contexto francés y la persecución nazi de los judíos. El guión, coescrito por la directora, es un canto a las buenas maestras, humanas e ingeniosas, capaces de modelar a las jóvenes generaciones.

Por lo que se refiere a Conducta, la traigo aquí no por la dirección o guión femenino, como las anteriores, sino por coincidir en ese canto al magisterio femenino y su impronta en niños como el protagonista, de once años. En este caso, el contexto cubano complica lo que ya es de entrada una familia desarbolada en torno a una madre drogadicta; algo que obliga al chaval a buscarse la vida. La valentía y generosidad de mujeres como la maestra Carmela (Alina Rodríguez), capaces de jugarse el puesto y casi la vida en pro de su vocación maternal desarrollada casi sin medios en un aula de primaria, ha conquistado no solo al público cubano, sino también al de Festivales como Málaga, donde obtuvo la biznaga al mejor largometraje sección Latinoamérica y los premios a la mejor dirección y mejor actriz.

De la educación, a la medicina, otra de las profesiones en que la mujer (ila ética del cuidado al fin!) estuvo presente desde hace más de un siglo. Con una puntualización: siempre como enfermera o auxiliar, a las órdenes del médico. Ahora Barbara (2012), interpretada por Nina Hoss, cuyo guión y dirección corresponde a Christian Petzold, es una médico, en el contexto de un hospital provinciano de la RDA al que llega desde un prestigioso hospital berlinés defenestrada por sus deseos de escapar del país. Una figura hermética, excelente profesional, pero ajena a las relaciones humanas: los diálogos escasean, el silencio y las miradas son, sin embargo, muy elocuentes. Vive planeando la huida con su pareja, con el miedo a la Stassi... Una vida dura, solitaria en una casa desconchada que no es hogar. Será su compañero de trabajo pero sobre todo la niña Stella, embarazada y herida, que ingresa en el hospital tras escaparse una y otra vez del reformatorio buscando una madre, quienes la hagan reaccionar con generosidad. Del egoísmo, en la pantaIla habitualmente propio del varón y que en su rol 
de mujer independiente ha asumido como coraza, a la ética del cuidado... hasta implicar su destino y cambiar la posible libertad por la de aquella desgraciada. La generosidad puede florecer incluso en un mundo sórdido, falto de libertades, que la estética cinematográfica refleja con verismo. Solo la música eleva el alma.

\section{EL CINE CONSAGRA LOS ROLES FEMENINOS. LA MUJER EN LAS COMEDIAS DE HOLLYWOOD: ÁNGEL DEL HOGAR / MUJER FATAL}

Este tipo de comedia, la screwball comedy bien estudiada por Echart (2004) y habitualmente escrita y dirigida por hombres, impulsa la ruptura de los estereotipos decimonónicos: la mujer era visualizada como ángel del hogar o mujer caída, femme fatale a la que hombres y sociedad nunca perdonan. En cuanto a esta última, Margarita Gautier (1936), dirigida por Cukor y magníficamente interpretada por Greta Garbo, fijó en pantalla el estereotipo que Dumas había creado en su libro La dama de las camelias (1848): la mujer marcada nunca alcanzará la felicidad y, en este caso, renunciará heroicamente al amor según las convenciones de la época. Mujeres así inundan el cine de género: el cine negro está cuajado de femme-fatale, sensuales pero masculinas en su capacidad de dominar al varón con sus atributos; Barbara Stanwiyck en Perdición (W. Wilder, 1944) o Lana Turner en El cartero siempre llama dos veces (Tay Garnett, 1946) son mujeres inolvidables.

Del ángel del hogar hay muchos ejemplos en pantalla, desde esa magnífica película Las uvas de la ira (1940), dirigida por J. Ford a partir de la novela de Steinbeck y en la que es ancilar el papel de la madre, mujer fuerte de la Biblia: un estereotipo de los Proverbios:

La historia del cine está llena de madres que han conmovido, conmocionado y cautivado. Hasta los años sesenta (...) el papel de la mujer en el cine clásico estaba íntimamente ligado a la maternidad. Los ejemplos son incontables y habitan en nuestro recuerdo los inmensos papeles de Lillian Gish en Intolerancia (D. W. Griffith, 1916); de Jane Darwell en Las uvas de la ira (John Ford, 1940; de Greer Garson en La señora Miniver (William Wyler, 1942), de Dona Reed en iQué bello es vivir! (Frank Capra, 1946), de Mirna Loy en Los mejores años de nuestra vida (William Wyler, 1946), de Mary Astor en Mujercitas (Mervin Leroy, 1949), de Sophia Loren en Dos mujeres (Vittorio de Sica, 1960) o de Anna Magnani en Mamma Roma (Pier Paolo Pasolini, 1962). Todas ellas son madres generosas y desprendidas, amantes de sus hijos, entregadas a su familia con una misma pasión y una devoción únicas

(Casas, 2015, p. 13).

La cita es demasiado larga pero sin desperdicio, como casi todo en el libro de Belén Ester Casas, En tierra de hombres. Mujeres y feminismo en el cine contemporáneo (2015). Tal vez una de las revisiones más ponderadas y actuales sobre el tema, que enlaza con, y va más allá en cuanto a diacronía, del excelente estudio de Ana Lanuza, El hombre intranquilo. Mujer y maternidad en el cine clásico americano (2011).

En este camino de reconversión de los roles patriarcales tiene un lugar privilegiado la deliciosa e imperecedera comedia de Cukor, La costilla de Adán (1949) que le debe tanto a los diálogos del matrimonio de guionistas. Aparece un nuevo tipo de mujer, como resultado de la incorporación femenina al trabajo y liderando la fila de profesionales, casi siempre sin hijos. Esta comedia pasa revista, con un fino sentido satírico, a un montón de asuntos relacionados con el matrimonio y la aportación femenina al mundo laboral masculino (Fijo, 2009). Encarna un tema favorito de comedia hollywoodiense, la guerra de los sexos; y lo hace de manera peculiar: Bonner and Bonner, fiscal y abogado defensor, respectivamente, se enfrentan en el juicio de los Attinger. A Doris, la esposa humillada, se le acusa de haber disparado sobre el marido infiel. Amanda (Katherine Hepburn), en un arranque feminista y de solidaridad con la acusada (por cierto prototipo de cuasianalfabeta marujona), acepta el caso frente al fiscal, su marido. La pareja, felizmente casada, con un nivel de alto standing, sin problemas, sin hijos se tambalea. Solo la inteligencia de ambos y la ruptura de los estereotipos habituales logrará el happy end, tan necesario en este tipo de comedias.

Si hubiera que señalar una película actual en que el rol materno sigue en pie con garra, una película modesta y de bajo presupuesto pero triunfadora en varios festivales, el primer puesto se lo llevaría la mexicana Los insólitos peces gato (2013), cuyo guión y dirección es femenino (Claudia Sainte-Luce). Con pocos medios y un argumento sencillo (joven enferma que coincide en un hospital con mujer madura y en vía terminal, madre de familia numerosa), la historia llega al espectador porque aborda problemas universales sin retórica alguna, desde el sentido común. $Y$ eso que la madre ha sido más que vapuleada por la vida y solo sus convicciones religiosas sirvieron como parachoques de una familia disfuncional y caótica, aun así unida por el cariño. ¡Hay esperanza! 
En el polo opuesto, en cuanto que su director y guionista es Nanni Moretti, Mia madre (2015), que acaba de triunfar en Cannes, ha recibido dos premios Donatello y ha sido nominada en los premios César, el festival de Sevilla... supone un cálido homenaje del director a su madre, en el que se considera como el más autobiográfico de sus films. En la ficción, una madura directora de cine (trasunto del propio Moretti) con problemas familiares y de pareja, decide dejar todo para dedicarse a su madre moribunda: ella en el lecho de muerte, sigue siendo la "mamma", la columna familiar. Familia desestructurada, stress... todo se altera ante la anunciada pérdida, en esta tragicomedia de emociones íntimas, sentimientos universales y grandes dosis de humor-como rezan los titulares-. Y que emblematiza la vida cotidiana de profesionales femeninas desgarradas entre dos mundos: el hogar y la calle.

La familia, el rol materno, los nuevos héroes han tenido su desarrollo incluso en el cine de animación, desde Toy Story (1995, Lasseter) hasta Los increíbles (1993, B. Bird), de la mano de Pixar, como ha estudiado con acierto Fumagalli en su libro Creatividad al poder. De Hollywood a Pixar pasando por Europa (2014). Un libro que, en palabras de Alberto Fijo, director de Fila Siete "trata sobre el arte industrial de contar historias (...) sistemas de escritura y producción de Hollywood (...) y cómo se diseñan las estrategias creativas y comerciales de un arte que mueve montañas de dinero y tiene una repercusión muy notable en la formación intelectual y emocional de cientos de millones de seres humanos" (Fijo, 2015, 30 diciembre).

\section{LOS NUEVOS ROLES: MADRE SOLTERA, EJECUTI- VA AGRESIVA O CAZADIVORCIOS, PERO TAMBIÉN LA PROFESIONAL}

Mujer, problemas de compatibilidad trabajo/hogar... Este es el punto de partida de Erin Brockovich (2000, Soderberg). Ya en la primera secuencia, el espectador se enfrenta a una joven madre divorciada, con escasa titulación y problemas para conseguir trabajo. Su aspecto es equívoco, la clásica femme fatale en versión contemporánea: parece que te lo pasas muy bien -le dirá el abogado al que ha exigido un trabajo para demostrar su propósito: recuperar su dignidad ante sí misma y la sociedad-. Este es el tema de fondo y por ello traigo a colación una película no excepcional, aunque sí taquillera (más de 250 millones de dólares) y nominada a varios Óscar, Bafta y Globos de Oro... de los que Julia Roberts consiguió el de mejor actriz. Borda un nuevo tipo de mujer: fa- milia mononuclear, trabajo fuera de la casa, pareja que hace de canguro, problemas para atender todo, stress, mucho stress... porque la mujer debe plegarse al competitivo esquema de sociedad, tan masculino, y dar mucho más que el varón para obtener el mismo status. El problema está en la sociedad que no arbitró modelos propios para el trabajo de la mujer según su especificidad y necesidades. El filme pone el dedo en la llaga de la macabra sociedad actual que despersonaliza y destruye al hombre.

Siempre en esta tesitura de enfoque feminista, $E n$ tierra de hombres (2005) cuya directora es Nicky Caro (1967, también productora y guionista neozelandesa), da un paso adelante en su ya sostenida filmografía que se abre en 2002, pero cuenta antes con televisión, cortometrajes y documentales desde el 92. Acusada de panfletaria, esta película tiene de fondo una historia real de discriminación sexual. El argumento lo posibilita: una madre soltera regresa a su pueblo al norte de Minnesota para trabajar en las minas de hierro. A su alrededor todo hombres, empezando por un padre incómodo por la situación y poco acogedor. Tendrá que pasar por todo tipo de vejaciones hasta crecerse y denunciar. Charlize Theron encarna con credibilidad un papel por el que recibió nominaciones al öscar, al BAFTA, a los Globos de Oro...

¿Qué sucede cuando la mujer cree encontrar la solución imitando el secular comportamiento del hombre seductor? Con este leitmotiv como telón de fondo, los Coen estrenaron su comedia Crueldad intolerable (2003), protagonizada por George Clooney y Catherine Zeta-Jones. Un relato ad hoc para plantear cuáles son hoy las armas femeninas en la relación de los sexos. El conjunto de mujeres que lidera la protagonista utiliza el matrimonio y subsiguiente divorcio como rápido medio de enriquecimiento; el hombre es un bien de usar y tirar. ¿Mujer objeto? ¡Hombre objeto! Qué busca la mujer del siglo XXI? Hay secuencias casi histriónicas en que el grupo de amigas al borde de la piscina de la gran mansión (ése es el espacio de su vida cotidiana donde el trabajo ni se conoce) deshoja la margarita de su aburrida secuencia vital: masajista, peluquero, juegos, viajes, alguna infidelidad matrimonial? "Demasiado arriesgado -concluyen-. Podría perder mi dinero y son asquerosamente ricas. Todas sienten que su vida es también asquerosamente aburrida.

De más calado, aunque siempre en el terreno de la comedia, Up in the Air (2009), dirigida por Jason Reitman y protagonizada por George Clooney, Vera Farmiga, y Anna Kendrick, muestra aspectos conflictivos del 
mundo laboral en una sociedad en que se despide a los viejos empleados sin escrúpulo alguno en función de reajustes económicos. Ese es el papel asignado a un George Clooney que vive literalmente "en el aire", de avión en avión, de hotel en hotel. Y ésa es la sociedad en la que deberá ser competitiva la mujer; una mujer que no le va a la zaga al varón, asumiendo en su carne los viejos roles de ángel del hogar y prostituta o, mejor, la vieja esquizofrenia masculina (el hogar y la querida). Pero ¿merece la pena esa combinatoria? ¿Cuánto debe pagar la mujer por situarse en una sociedad que no valora más que el dinero? Paradójicamente, será el tiburón, el viejo seductor quien, absolutamente solo en un aeropuerto al final del filme, acabe añorando el hogar que nunca tuvo.

La película tiene sus matices y su desdoblamiento femenino. Es la mujer cuarentona (Vera Farmiga) quien se instaló con naturalidad en la esquizofrenia que se descubre al final: matrimonio clásico con hijos (ahí es la madre tradicional) y ejecutiva yuppie, ligona y competitiva como la que más, liberada en el sentido más tópico del término. Por ello, no es solo mero divertimento la secuencia en que ambos protagonistas muestran sus poderes mediante el contrapunto de tarjetas (Visa, Master Card...), símbolo de su poderío cosmopolita. Sin embargo, conseguir una cifra altísima de millas (objetivo último de Clooney) se muestra al final absolutamente ridículo: no hay amor, ni hogar, ni amistad en su vida. Pero además, la película tiene su desdoblamiento femenino por medio de la ejecutiva super jovencita, recién graduada con honores, que llega a la empresa desbancando a los viejos tiburones. Al final, tira la toalla: no puede soportar la inhumanidad de los despidos, la falta de trato humano, la ausencia de amor, paradójicamente abandonada por el novio al que ha seguido a provincias posponiendo mejores ofertas profesionales. $\mathrm{Y}$, tras su primer deslumbramiento ante la ejecutiva bella y talludita, será ella la consejera improvisada que se encargue de hacer ver a Clooney algo obvio: vivir así no tiene sentido. Representa esa juventud, profesionalmente agresiva y bien preparada, que ya ha visto hasta dónde llegó la liberación de sus madres. ¿Un modelo a imitar? No, gracias! (Caballero, 2012).

Algunas, aún no maduraron. Es el caso de la protagonista de Young Adult (2011), una muy creíble Charlize Theron, escritora en crisis profesional y amorosa. Recién divorciada, emprende un viaje al pueblo de su niñez para afirmarse frente a quienes no se atrevieron a volar acogotados por una vida rutinaria. No sin sorpresa, comprenderá que la única inmadura y fraca- sada es ella: los demás sacaron adelante una familia que, con los problemas y límites consabidos, llena sus vidas. De nuevo Reitman, que suele apostar por guiones interesantes, dirige un guión de Diablo Cody, repitiendo el tándem que tan bien bordó en Juno (2007), un film muy joven y posmoderno sobre el embarazo adolescente, que da qué pensar.

Otras, son fruto del 68, madres que dejaron atrás todo (hogar, hijos...) por seguir una vocación profesional. Y al cabo de los años, con melancolía y cierta acritud, se preguntan si mereció la pena. Es la historia de Ricky (2015, J. Demme) interpretada por una rockera Meryl Streep que hace una genial interpretación musical y se crece sobre el guión a su medida, de nuevo en manos de Diablo Cody.

Cazatalentos, ejecutivas, intelectuales... Gravity (2013) dirigida por el mexicano A. Cuarón va más allá: la mujer puede ser astronauta, la Dra Ryan Stone, una Sandra Bullock que borda el papel junto a su compañero Georges Clooney (Kovalski en la ficción), en lo que se ha definido como "un misterioso y denso thriller de ciencia ficción magistralmente dirigido y visualmente impresionante". Presentada en el Festival de Venecia, obtuvo varios Óscar (mejor director, banda sonora, montaje, fotografía, efectos visuales, edición de sonido... además de nominaciones a mejor actriz). Otro tanto sucedió con los BAFTA y en los Globos de Oro, Cuarón obtuvo el de mejor director. Ha sido una película taquillera, que hizo más de 616 millones de dólares. Esa astronauta a bordo del trasbordador espacial Explorer que, tras una serie de accidentes queda sola y conseguirá, no sin denodado esfuerzo, regresar con bien a la tierra, arrastra sus traumas maternales hacia el espacio sideral. Y será allí, entre la oscuridad más tenebrosa suavizada por algunas estreIlas, donde vivirá su particular catarsis. Porque en esta película de ciencia ficción, la mujer es madre.

\section{EL PRIMER FEMINISMO DE LA IGUALDAD QUEDÓ ATRÁS: EL DESENCANTO FEMENINO}

El trabajo de la mujer fuera de la casa, fruto en su origen de las dramáticas circunstancias generadas por las dos guerras mundiales, va a obligar a romper estereotipos. No serán sólo ellas sino también ellos quienes se interesen por el fenómeno, como lo demuestran títulos que ponen de manifiesto el desencanto de la mujer madura ante su rol tradicional: asunto reiterativo en las películas de W. Allen: Annie Hall (1977), Delitos y faltas (1989), Maridos y mujeres (1992), o Poderosa Afrodita (1995). No es el único y en los noventa tuvieron éxito por este motivo películas como 
Telma and Louise (1991), de R. Scott; Tomates verdes fritos (1991), de J. Avnet; Magnolias de acero (1989) de Ross, un excelente canto al amor fecundo y sobre todo a la solidaridad femenina; o ya en el ámbito español El pájaro de la felicidad (1993), de Pilar Miró; Cómo ser mujer y no morir en el intento (1991), que rodó Ana Belén sobre el texto de Carmen Rico-Godoy; o Mujeres al borde de un ataque de nervios (1988), de Almodóvar que recibió cuatro Goyas. La mujer frena su carrera cotidiana dentro y fuera del hogar y revisa su vida a veces con un tono amargo: se siente fracasada al cabo de los años. El cine no hace sino reflejar la sociedad y estas cosas suceden día a día.

Al desencanto de las marujas abrumadas por la rutina, empieza a superponerse el desconsuelo de las más jóvenes ante las trampas de la emancipación en una sociedad que no les apoya. Los nuevos modelos femeninos, por ejemplo el de la yuppie que supedita la familia al triunfo profesional, ahora parecen en entredicho: The Paper. Detrás de la noticia (1994), de R. Howard plasma el alienante egoísmo de quien opta por algo así. Por su parte y desde la comedia, la divertida En sus zapatos (2005) cuestiona los roles de las dos hermanas, la yuppie agresiva y la frívola ligona, para romper su incomunicación y acercarlas en un radical cambio de vida que permite una mirada a los otros; lo que en definitiva, les hace crecer como personas. Por fin, Deliciosa Martha (2001), de la alemana Sandra Nettelbeck enfrenta a esa jefa de cocina de un sofisticado restaurante francés de Hamburgo, soltera y volcada en su trabajo, a las obligaciones de una madre adoptiva. Su orgullo y suficiencia caen ante las nuevas responsabilidades y los modos de hacer de su colega, un chef latino con un modo mucho más lúdico y humano de encarar la vida cotidiana. Porque ha llegado el tiempo en que las mujeres exigen a la vida mucho más que el simple triunfo profesional. En ese sentido, tiene mucho que aportar ya desde el título la película de la francesa Cécile Telerman, Por qué las mujeres queremos siempre más (2005).

Y si hablamos de desencanto, no por conocida conviene olvidar El diablo se viste de Prada (2006, Frankel), adaptación de un bestseller de Lauren Weisberger (2003). Es la historia de la segunda ayudante de la redactora jefe de la revista Runway, Miranda Priestly, inspirada en Anne Wintour, la editora de Vogue en Estados Unidos, mujer poderosa donde las haya. La tesis de fondo es obvia: para triunfar en lo profesional hay que renunciar a lo personal y familiar. Meryl Streep y Anne Hathaway sostienen un duelo interpretativo de alta tensión, en medio de un mundo tan competitivo que destroza a los seres humanos: algo que comprenderá la joven Andy Sachs y que le llevará a renunciar a todo, cuando parece haberse instalado en el canon. Sátira despiadada del mundo de la publicidad y la moda, fue nominada y ganó varios premios (interpretación, vestuario...).

\section{LA RUPTURA DE LA FAMILIA... AÚN ASÍ, LA FAMILIA IMPORTA}

El trabajo femenino fuera de la casa genera indudables conflictos e inevitablemente impone toda una revisión de la familia patriarcal, que deberá reconvertirse para hacer frente a los nuevos retos, o sucumbirá dejando tras de sí jirones rotos, divorcios y traumas en los hijos que los sufren: Kramer contra Kramer (1979), de Benton, uno de las primeras reivindicaciones femenistas. El cine ha recogido el guante: Un mundo perfecto (1993), de Eastwood, es un ejemplo de la añoranza del hogar por parte de quienes lo perdieron. En el ámbito español, Solas (1999) retrata el problema en las dos mujeres (madre e hija) protagonistas, insistiendo en la soledad angustiosa en que viven todos los personajes. Al matrimonio tradicional en que la mujer no tiene voz ni voto (el caso de la madre) sucede la vida ¿liberada? de la pareja moderna. No obstante, el camionero demuestra con su actuación un absoluto desprecio hacia su novia, ese ser femenino de "usar y tirar". La mujer siempre pierde. Y la esperanza, curiosamente, arranca de los viejos, de quienes saben vivir con generosidad y desprendimiento, pensando en el bien de los otros.

Por su parte un drama coetáneo, Cosas que importan (1999), de C. Franklin se orienta también a la superación de los estereotipos: la madre, una Meryl Streep aparentemente simplona pero siempre atenta a los problemas de los otros en su deseo de hacer familia, tal vez aporte más a la sociedad que el imponente profesor (William Hurt, en realidad un cobarde y frustrado escritor) o la agresiva joven periodista que es su hija. La joven (Renée ZeIlweger) acabará valorando y asumiendo el código materno, si bien adaptado a los nuevos tiempos. Y el dolor ante el cáncer materno será un acicate para madurar. Tres años antes (1996) se había estrenado una película de Jerry Zaks, La habitación de Marvin, en la que dos hermanas dan vida a dos roles femeninos contrapuestos: el maternal de la ética del cuidado, a cargo de una Diane Keaton que entregó su vida generosamente al cuidado de su familia, en una aparente anulación que le ha hecho profundamente feliz; y el "rol liberado" de la joven 
(Meryl Streep) que se escapó de casa para "realizarse" al detectar los primeros problemas. Años después, separada y madre de dos hijos, se resiste a cambiar a pesar de su fracaso. Tras el rechazo inicial, el reencuentro con la hermana ahora también enferma le irá llevando a la madurez, voluntariamente comprometida, de quien aprendió que la felicidad se encuentra en el sacrificio y no al revés. Y que apostar por las personas, en este caso su hijo, un jovencísimo Leonardo di Caprio, tiene su recompensa. Algo que sucede también en una película española, Héctor (2004), de Gracia Querejeta, donde resultan muy patentes los desencuentros entre padres e hijos.

Cada vez más, se confirma el rescate de la familia, desde ángulos complementarios que parten de la familia patriarcal revigorizada por parejas jóvenes, que se mueven en la óptica de la corresponsabilidad y han olvidado los viejos esquemas de sumisión/ anulación femenina. Es la familia de Lo imposible (2012), una película espectacular como corresponde a la grabación y vivencia de un tsunami, dirigida magistralmente por Juan Antonio Bayona, con Naomí Wats y Ewan McGragor, que obtuvo catorce nominaciones a los Goya, de los cuales consiguió cinco, incluido el de mejor director. Si la naturaleza es la obligada y grandiosa protagonista, no menos entidad tienen los seres humanos $y$, en concreto, esa familia de vacaciones navideñas en Tailandia que debe luchar aguerridamente por la supervivencia. iLa unión hace la fuerza! El viejo refrán se confirma en unos personajes de perfiles muy creíbles, que rescatan esa célula, primer motor de la sociedad, que fue siempre la familia.

La familia importa, aunque sea tan peculiar como La familia Bellier (2014, E. Lartigau): todos sordomudos, excepto la hija adolescente, su ayuda en la granja y puente hacia la comunidad en la que se inserta con audacia el pater familias, hasta el punto de proponerse como alcalde. En esta familia alegre y extrovertida no hay traumas que valgan. Al final, la protagonista deberá optar entre seguir su camino vocacional (la música) o mantenerse como sostén del grupo. Y lo hará, apoyada en la generosidad de los suyos, en una comedia melodramática, no excepcional pero muy amable y bien interpretada, con un respaldo musical interesante.

En resumen: por la familia se apuesta incluso in extremis, en familias desarticuladas y cuasi grotescas como la de Pequeña Miss Sunshine (2006, J. Dayton y V. Faris) a años luz de la familia patriarcal de Hollywood. Un viaje de tres días hacia el Oeste en una destartalada furgoneta parece acercarla a Las uvas de la ira. Pero ahora la madre no es la mujer fuerte de la Biblia, sino una pobre mujer sobrepasada por el grupo: un abuelo que esnifa coca, un hijo gay y suicida, un marido fracasado, un adolescente taciturno....Un absurdo grupo de inadaptados, tan reales como la vida misma, que se unen no para buscar trabajo como en la película de Ford, sino para apoyar a la pequeña del clan, gordita y gafotas, empeñada en participar en un concurso de belleza. Más allá de su histriónica excentricidad, el guión tiene su mensaje solidario: la familia ante todo, que le hizo merecedora de 2 Oscar, 2 BAFTA, el premio del público del Festival de San Sebastián y casi diez nominaciones más.

Nuestro último verano en Escocia (2014, A. Hamilton y G. Jenkin) una divertida tragicomedia familiar, con ciertos ribetes de la anterior, ha pasado con éxito por las taquillas británicas y obtuvo el Premio del Público en la Seminci de Valladolid. Una vez más (como tantas, en la vida y en la pantalla), una pareja al borde del divorcio decide viajar con sus tres hijos a Escocia en pro de la reconciliación. Allí se encontrarán con sorpresas al reunirse con el abuelo. Humor, situaciones límite, la mirada infantil que suaviza el día a día, un auténtico campo de minas, en lo que Jerónimo José Martín ha definido como "una pequeña gran película, sin alardes narrativos o técnicos, y con una limitada antropología de fondo, pero bien rodada, mejor interpretada (Rosamund Pike y David Tennant) y con un gran corazón" (Martín, 2015, 28 mayo).

El tema no se agota: Los descendientes (2011), escrita, producida y dirigida por Alexander Payne, otro de los grandes y protagonizada por George Clooney, lo centra en un abogado de Honolulú, un yuppie al que se le derrumba la vida tras un accidente mortal de su mujer, que le enfrenta a la cruda realidad: estaba a punto de abandonarle y era una desconocida para él. Como lo son sus hijas, adolescentes a las que aprenderá a querer; como también aprenderá a volver a las raíces, las tierras familiares que pensaba vender como negocio especulador. ¡No hay bien que por mal no venga!

No se agota porque están los viejos, cascarrabias, medio alhzeimer, inadaptados y viviendo de prestado en casa de unos hijos cuya vida, atenazada por un trabajo cada vez más deshumanizador, les impide hacerse cargo de ellos. Nebraska (2013), también dirigida por Payne y muy nominada y premiada, puede ser un ejemplo planteado con humor, de esta temática. 


\section{LA FAMILIA EN EL TERCER MUNDO}

La familia importa. En el primer mundo tal vez, pero más en Oriente. Comenzando con una deliciosa película del taiwanés Ang Lee, Comer, beber, amar (1993), que aborda las relaciones de un cocinero chino y sus tres hijas. La pujante modernización europea hace trastabillar un mundo de ritmo lento, anclado en una tradición de siglos donde el respeto de los mayores era fundamental. Las tres hermanas deberán encontrar el punto medio en ese proceso. $Y$ a fe que lo consiguen, cada una a su modo. La película es amable y muestra una vez más la importancia que Lee confiere a la familia, como ha declarado en muchas entrevistas.

Yimou es un gran cineasta: no cabe duda de que supo bordar la infatigable psicología femenina en Qui-Ju, una mujer china (1992); o la exquisita delicadeza de la mujer del maestro chino, en su doble versión de adolescente y anciana, en El camino a casa (2000), una película estéticamente muy cuidada, con su alternancia de sepia y colores vivos para marcar los dos tiempos, pasado y presente. Pero no es el único: los orientales han descubierto que la familia es un valor importante. Si se hunde, todo se va al garete. $Y$ ahí está, imponente, en sus filmes: desde Sang Woo y su abuela (2002) de la directora coreana Lee-JungHyang (1964), un ejemplo de dirección femenina en el mundo oriental, no tan abundante por otra parte; hasta la saga de Yamada, que parece no cesa. Siguiendo a su maestro Ozu en Cuentos de Tokio (1953), nos propone una sobria y melancólica visión del paso del tiempo: los abuelos pueden llegar a ser un pequeño "estorbo" en nuestra sociedad contemporánea, pero la exquisitez oriental impide la tragedia. En su filmografía, la familia es un valor de primera magnitud: EI ocaso del samurai (2002), Una familia de Tokio (2013) y La casa del tejado rojo (2014) lo ponen de manifiesto con una delicadeza sin par, profundizando en historias sencillas y cotidianas, donde lo intergeneracional siempre es algo a tener en cuenta. Recientemente, otra película coreana, Oda a mi padre (2014), dirigida por Youn Jk reescribe la reciente historia de la guerra de Corea desde los ojos de un niño / adolescente, capaz de hacerse "padre" del clan familiar ante las adversas circunstancias. Un melodrama ambicioso, espectacular, muy bien llevado desde el punto de vista técnico, que no teme tocar sin pudor y para bien la fibra sensible del espectador.

Otro grupo en el que la familia importa es el de la minoría latina en Estados Unidos, cuya contraposición de culturas ha sido llevada al cine en varias oca- siones desde la óptica masculina: Sólo los tontos se enamoran (1997), con una fantástica Salma Hayek, o Spanglish (2004), de L. Brooks. En la última, está bien vista aunque sea tópica, la disyuntiva cultural en la hija, la generación que se plantea el incardinamiento en los Estados Unidos: ¿querrá perder o no su identidad latina? Por supuesto, el foco está algo distorsionado y se centra en los gags divertidos más que en este asunto, que estalla al final de una comedia romántica con ribetes bufos. En otra película "latina", Las mujeres de verdad tienen curvas (2002), dirigida por Patricia Cardoso, se observa de nuevo la contraposición de ese mundo (en este caso una familia al completo con sus varias generaciones) y el contexto anglo. Afirmación de cánones femeninos a lo diosas de la fertilidad antigua, como reto a las anoréxicas modelos de hoy, e incardinación en una modernidad plural propia de ese país de aluvión. Lamentablemente Cardoso se ha quedado en la superficie sin descender a mayores trascendencias: los jóvenes no se plantean sutilidades morales y están ya lejos de las viejas normas.

Una segunda madre (2015, Anna Muylaert) podría considerarse, salvando las distancias, una especie de reescritura de Spanglish, en cuanto que la llegada de la hija provoca conflictos en el statu quo creado entre la familia y su servidora. Como telón de fondo, la emigración en busca de un mundo mejor... La lucha de la mujer abriéndose paso en un mundo competitivo... hay varias películas que desde vertientes distintas, contraponen el Primer y el Tercer Mundo: La pequeña Venecia (Shun Li y el poeta) (2011), opera prima del italiano Andrea Segre, también autor del guión sobre el drama de la emigración china malviviendo en Europa, con un trabajo a destajo en las fábricas italianas. Todo para ahorrar el dinero que permita traer a la familia. Una vida muy dura paliada solo por la amistad / amor de un sencillo lugareño...

En el marco de la multiculturalidad, Un viaje de diez metros (2014, L. Hallström) cuenta los avatares de una familia india, los Kadam, que se establece en Francia instalando un restaurante frente al exquisito local, estrella Michelin incluida. ¿Cómo abrirse paso en la competencia culinaria? ¿Cómo sobrevivir a los recelos culturales y racistas? Los desencuentros y rechazos iniciales, inevitables en la línea de la vieja controversia civilización / barbarie, o Primer/ Tercer mundo, acaban solventándose a favor de la convivencia interracial, futuro deseable para un mundo cada vez más global. Algo que no se consigue sin esfuerzo y generosidad por ambas partes. 


\section{VIOLENCIA Y FALTA DE LIBERTADES FEMENINAS}

La violencia de género por desgracia está muy de moda en los medios: maltrato, atentados de cualquier tipo contra la libertad femenina... Tal vez una de las películas más impresionantes y medidas a la vez en este asunto sea Te doy mis ojos (2003), de Icíar Bollaín. Medida en cuanto que consigue escapar al enfoque sectario o partidista. El problema es grave: los celos del marido destrozan la vida familiar y enloquecen a la mujer, quien se debate entre el indudable cariño a su hombre y el miedo ante sus violentas reacciones. Hay algo más: la dignidad femenina, el reclamo de un espacio propio a través del trabajo fuera de la casa y las relaciones con las amigas. Bollaín no se ceba en el macho: él también es una víctima del machismo de siglos que rige especialmente las sociedades latinas. $Y$ una víctima incapaz de superar sus límites, aunque se esfuerce a través de la terapia.

Quiero poner sobre el tapete una cuestión muy debatida: ¿debe ser la mujer quien denuncie el maltrato, en este caso en la pantalla? O, lo que es lo mismo: ¿es tan decisivo el género a la hora de afrontar un problema social ? ¿Es menos real o de segunda clase la denuncia en películas como Kandahar (2001), de Makhmalbaf; Osama (2003), de S. Barmak; o María, Ilena eres de gracia (2004), de Joshua Marston, porque la dirección esté en manos masculinas? Puedo asegurar que la absoluta falta de libertad, de aire para respirar y vivir de la mujer en el Afganistán de los talibanes, y el drama de la droga en Colombia han sido magníficamente tratados en las películas reseñadas. Incluso el laconismo y las elipsis, los silencios y miradas están muy cerca de una estética supuestamente femenina. Y, como siempre, están las felices colaboraciones: No sin mi hija (1990), dirigida por Brian Gilbert sobre guión de William Hoffer, descansa en el testimonio verídico de Betty Mahmoody que fue un bestseller arrollador.

Violencia que se ejerce de muchos modos en el lejano Oriente: $Y$ ahora cadónde vamos? (2011) de la joven directora libanesa Nadine Labaki, también protagonista y responsable en parte del guión, es una comedia melodramática y coral donde toda una población femenina, la mayoría viudas, desgarrada por las guerras entre cristianos y musulmanes, se une para inventar estrategias que impidan las muertes seculares de sus hijos. De lo privado a lo público: unos años antes, la joven Labaki se dio a conocer con Caramel (2007): una peluquería, ámbito femenino por excelencia, reúne a un grupo de mujeres muy diversas, pero todas deseosas de un mundo más libre.
Libertad por la que se sigue clamando: la reciente Mustang (2016), dirigida por la turca Deniz Gamze Ergüven, lleva a la pantalla el drama de cinco hermanas afectadas por las tradiciones y la falta de libertad imperantes todavía hoy. A las primeras secuencias de compañerismo, amigable, inocente en un idílico marco abierto junto al mar, se suceden tras las consabidas denuncias de "inmoralidad" por parte de los viejos, la clausura en el hogar y la búsqueda de marido, mientras se las forma en tareas propias del ángel del hogar, sin acceso alguno a la cultura, sin libertad de elegir pareja. Las consecuencias serán catastróficas para la mayoría, si bien la película elude presentar escenas crudas de forma abierta. No estamos en la trilogía de Deepa Mehta, pero casi...

\section{UNA SAGA DE DIRECTORAS}

La familia y los roles femeninos están potenciados también en una de las primeras grandes directoras, B. Streisand. Existe un universo Streisand, un perfil femenino, una valoración de la familia, unos temas: los traumas de la niñez, el deseo de la mujer de ser conocida y valorada por el hombre como persona, amiga y compañera, su reclamo de un espacio en que desarrollar sus ideales... Muchas de estas cuestiones quedaron plasmadas en Tal como éramos (1973), de S. Pollack, donde la vocación de la protagonista se impondrá a los sentimientos, aunque le cueste la ruptura de pareja y el abandono de su auténtico amor de juventud. Un tema de fondo que se reitera en su filmografía bajo circunstancias e historias diversas. Tanto Loca (Nuts) (1987) como El príncipe de las mareas (1991) sitúan en la infancia familiar los traumas que el adulto arrostrará sin remisión. A pesar de ello, el mensaje es claro: la familia merece la pena, los problemas se solucionan compartiendo y la mujer tiene mucho que ofrecer. El amor tiene dos caras (1996) repite el binomio actriz y directora, sobre guión de otros. Una película ¿ligera? que, entroncando con las ideas expuestas en Yentl, hila más fino sobre la personalidad femenina: ni sexo deshumanizado, ni simple compañerismo por más estimulante que sea; el amor en la pareja moderna funde con éxito esas dos caras. Y si no... es otra cosa. La película sale al paso de ciertos feminismos extremos que impiden a la fémina desarrollar todas sus facetas.

Entre las directoras europeas consagradas, Susanne Bier (1960), la nominada y premiada directora danesa de Hermanos (2004), Después de la boda (2006), Cosas que perdimos en el fuego (2007), En un mundo mejor (2010), y algunas más quizá no tan conseguidas, es una 
de las cineastas que más se centran en mujer y familia. Formó parte del movimiento Dogma y ha rodado ya más de diez largometrajes. Es una directora con cosas interesantes que decir y se caracteriza por las historias fuertes: familia de clase alta que lo tiene todo pero... no es tan feliz. $Y$ en ese universo acotado irrumpe el dolor: cáncer, droga, súbito asesinato del marido... En un mundo mejor quizá sea la más completa: dos escenarios, un campo de refugiados africano y Dinamarca (Tercer y Primer Mundo) y violencia en ambos. Mensaje pacifista de fondo: esta directora pone a sus personajes contra las cuerdas, pero los salva al final. Mejor dicho: se salvan ellos, con esfuerzo, con la comprensión mutua; porque apuesta por un modelo de corresponsabilidad, con el que todos triunfan. Y tiene mérito porque arranca de tópicos previsibles: doctor idealista, niño despistado, niño malvado, madre superada por la vida cotidiana en un hogar desestructurado. Sus imágenes transpiran verdad, contención y dureza emocional.

Repetir aquí la filmografía de directoras españolas tan consagradas como Isabel Coixet, Icíar Bollaín o Gracia Querejeta... parece innecesario. Otras muchas inundan la pantalla y van siendo recogidas en los estudios pertinentes, como el libro Directoras de cine español. Ayer, hoy y mañana, mostrando talentos (2012, Núñez Domínguez, Silva Ortega, Vera Balanza). Precisamente por su juventud y porque todavía no ha pasado a ser parte del corpus, quiero señalar a la joven Leticia Dolera.
Requisitos para ser una persona normal (2015), con guión y dirección de la citada actriz y ahora directora, premiado en el Festival de Málaga, es una cinta refrescante y posmoderna, muy de hoy y contada con naturalidad, buen ritmo y desparpajo por una protagonista treintañera (la propia directora, se trata de su opera prima) empeñada en "ser normal". Pero eso (tener trabajo, amigos, amor exclusivo, una familia unida...) parece algo utópico en nuestro habitat. La estética naif, que ella reconoce inspirada en Juno (2007, Reitman), el humor, la ausencia de dramatismo y la ternura sin cursilería sostienen una comedia con mucho más calado de lo que a primera vista pudiera parecer. Se impone una reflexión sobre la sociedad que hemos dejado a nuestros jóvenes que miran con asombro y cierto halo inocente desde los ojos de Dolera. Una de las jóvenes promesas en la dirección española.

A la hora de cerrar un repaso siempre insatisfactorio por lo inabarcable de una materia cada vez más rica y con matices más sutiles y diversificados (focalizaciones sobre la mujer en los films, directoras, guionistas, productoras...) pienso en Meryl Streep, una actriz sensacional que borda todas sus películas: si pudiera trazarse un hilo conductor desde La habitación de Marvin a Ricky (en el fondo repiten el mismo esquema: abandono de responsabilidades en pro de una supuesta felicidad) tal vez pudiera escribirse esa historia femenina de "liberación" que le ha pasado factura a la mujer.

\section{BIBLIOGRAFÍA}

Aresté, J. M. (2006). Escritores de cine. Relaciones de amor y odio entre doce autores y el celuloide. Madrid: Espasa.

Arranz, F. (dir), Aguilar, P., Callejo, J., Pardo, P., París, I. y Roquero, E. (2010). Cine y género en España. Una investigación empírica. Madrid: Cátedra.

Caballero, M. (1998). Femenino plural. La mujer en la literatura. Pamplona: Eunsa.

Caballero, M. (ed.) (2011). Mujeres de cine. 360 o alrededor de la cámara. Madrid: Biblioteca Nueva.

Caballero, M. (2012). Las trampas de la emancipación: mujer y trabajo en el cine del siglo XX. En: Almela, M., García Lorenzo, M., Guzmán, H. y Sanfilippo, M. (coords). Mujeres a la conquista de espacios. Madrid: UNED, pp. 51-62.

Caballero, M. (2012). Las trampas de la emancipación. Literatura femenina y mundo hispánico. Madrid: Biblioteca Nueva.
Caparrós Lera, J. M. (2007). Guía del espectador de cine. Madrid: Alianza.

Casas, B. E. (2015). En tierra de hombres. Mujeres y feminismo en el cine contemporáneo. Madrid: Encuentro.

Fijo, A. (2009). 100 clásicos. Madrid: Palabra.

Fijo, A. (ed.) (2004). Breve encuentro. Estudios sobre 20 directores de cine contemporáneo. Madrid: CIE/Dossat.

Fijo, A. (2015, 30 diciembre). Creatividad al poder. De Hollywood a Pixar pasando por Europa. Fila Siete. [En línea]. Disponible en http://filasiete.com/ noticias/libros-de-cine/creatividad-alpoder-de-hollywood-a-pixar-pasandopor-europa/

Frago Pérez, M., Martínez-Illán, A. y Cuevas Álvarez, E. (eds.) (2006). Personaje, acción e identidad en cine y literatura. Madrid: Eiunsa.
Fumagalli, A. (2014). Creatividad al poder. De Hollywood a Pixar pasando por Europa. Madrid: Rialp.

García Pelegrín, J. (2008). El cielo sobre Hollywood. Madrid: Palabra.

Lanuza, A. (2011). El hombre intranquilo. Mujer y maternidad en el cine clásico americano. Madrid: Encuentro.

Martín, J. J. (2015, 28 mayo). Nuestro último verano en Escocia. Fila Siete. [En línea]. Disponible en http://filasiete.com/peliculas/ultimo-verano-escocia-65/

Montero, J. y Rodríguez, A. (coords.) (2005). El cine cambia la historia. Madrid: Rialp.

Montero, J. y Paz, M. A. (2011). Lo que el viento no se llevó. El cine en la memoria de los españoles (1931-1982). Madrid: Rialp.

Núñez Domínguez, T., Silva Ortega, M. y Vera Balanza, T. (coords.) (2012). Directoras del cine español. Ayer, hoy y 
mañana mostrando talentos. Sevilla: Secretariado de Publicaciones de la Universidad de Sevilla/ RTVA/ Fundación Audiovisual de Andalucía.

Orellana, J. (2011). Como en un espejo. Drama humano y sentido religioso en el cine contemporáneo. Madrid: Encuentro.

\section{ANEXO}

MUJER/ACCESO AL TRABAJO: YentI (1983, B. Streisand), Sentido y sensibilidad (1995, A. Lee), Mansfield Park (1999, P. Rozema), An education (2010, L. Schefig), La historia de Marie Heurtin (2014, J.-P. Amèris), La profesora de historia (2014, Marie-Castille Mention Schaar) y Conducta (2014, E. Daranas).

FAMILIA: Las uvas de la ira (1940, Ford), La costilla de Adán (1949, Cukor), Matrimonio de conveniencia (1990, P. Weir), Una historia del Bronx (1993, R. de Niro), Comer, beber, amar (1993, A. Lee), La habitación de Marvin (1996, J. Zaks), Agnes Browne (2000, A. Huston), Héctor (2004, G. Querejeta), Después de la boda (2006) y En un mundo mejor (2010, S. Bier), Los descendientes (2011, A. Payne), Un dios salvaje (2011, Polanski), Lo imposible (2012, J. A. Ba-
Orellana, J. y Martínez Lucena, J. (2012). Celuloide posmoderno. Narcisismo y autenticidad en el cine actual. Madrid: Encuentro.

Teruel, P. J. (2012). Cerebro, mente, cuerpo, persona. Antropología cinematográfica (Textos docentes). Madrid: Fundación Universitaria San Pablo CEU.

yona), Nebraska (2013, A. Payne), El pasado (A. Farhadi, 2014), La casa del tejado rojo (2014, Y. Yamada), Oda a mi padre (2014, Youn Jk), La familia Bellièr (2014. E. Lartigau), Los insólitos peces gato (2013, Cl. Sainte-Luce).

NUEVOS ROLES FEMENINOS: La costilla de Adán (1949, Cukor), Eva al desnudo (1950, Mankievicz), Deliciosa Martha (2001, S. Nettelbeck), Crueldad intolerable (2003, Coen), En sus zapatos (2005, Hansom), Por qué las mujeres queremos siempre más (2005, C. Télerman), Up in the Air (2009), Juno (2007) y Young Adult (2011), J. Reitman; El camino a casa (1999) y Amor bajo el espino blanco (2010, Zh. Yimou), La delicadeza (2011, D. y St Foenkinos), Barbara (2012, Ch. Petzold), Hannah Arendt (2012, M. Von Trotta), Eine Teure
Tomás y Garrido, M. C. y Tomás y Garrido, G. M. (2004). La vida humana a través del cine. Cuestiones de antropología y bioética. Madrid: Eiunsa. Ediciones Internacionales Universitarias.

Affaire (S. Gobler, 2013), Ida (2013, P. Pawlikowski), Gravity (2013, A. Cuarón).

MULTICULTURALISMO: Solo los tontos se enamoran (1997, A. Tennant), Flores de otro mundo (1999, I. Bollaín), Bailar en la oscuridad (2000, L. von Trier), En un lugar de África (2001, C. Link), Spanglish (2004, L. Brooks), La boda del monzón (2001) y El buen nombre (2007, M. Nair), La pequeña Venecia (2013, Segre), Un viaje de diez metros (2014, L. Hallström), La segunda madre (A. Muylaert, 2015).

VIOLENCIA DE GÉNERO y FALTA DE LIBERTADES: Osama (2003, S. Barmak), María llena eres de gracia (2004, J. Marston), Te doy mis ojos (2003), Agua (2005, D. Mehta), Miss Bala (2012, G. Naranjo), Mustang (2015, D. Ganze Ergüven). 